\title{
Prevalência de acidentes ocupacionais e perfil de vacinação contra Hepatite $B$ entre estudantes e profissionais da odontologia: um estudo piloto
}

\section{Prevalence of occupational accidents and vaccination profile against Hepatitis B between students and dental professionals: a pilot study}

\author{
Epitácio Pessoa de Andrade Neto ${ }^{1}$, Caio de Santiago Dutra ${ }^{1}$, Vilma Lima ${ }^{2}$, Paula Goes ${ }^{3}$
}

\begin{abstract}
RESUMO
Objetivo: Determinar a prevalência de acidentes ocupacionais e situação vacinal contra Hepatite B entre acadêmicos e profissionais da área de Odontologia. Materiais e Métodos: Este estudo piloto, de caráter descritivo, utilizou durante a coleta de dados um questionário aplicado composto por itens de identificação, características do acidente e conduta frente à exposição. A amostra foi constituída de acadêmicos e profissionais da área de Odontologia do município de Quixadá-CE. Resultados: Foram entrevistados 32 indivíduos, sendo que $59,0 \%$ deles relataram nunca ter sofrido acidente, enquanto $41,0 \%$ afirmaram ter sofrido algum tipo de acidente ocupacional. Dentre os acidentados, a maioria era mulher (62,0\%). Os instrumentais mais relacionados aos acidentes foram: agulha gengival e sonda exploradora. Na maioria das vezes, os acidentes foram do tipo percutâneo. Todos os participantes $(100,0 \%)$ afirmaram estar utilizando todos os equipamentos de proteção individual. Quanto à situação vacinal contra hepatite $\mathrm{B}$, apesar de a maioria dos entrevistados ter relatado vacinação prévia (83,0\%), apenas $23,0 \%$ deles apresentaram sorologia para anticorpo anti-Hb. Conclusão: a prevalência de exposição ocupacional a material biológico foi considerada alta e a situação vacinal contra hepatite B ainda encontra-se precária entre os graduandos e profissionais de Quixadá.
\end{abstract}

Descritores: Saúde do trabalhador. Hepatite B. Exposição ocupacional.

\section{INTRODUÇÃO}

As condições de trabalho dos cirurgiõesdentistas e auxiliares de consultório odontológico fazem com que eles estejam expostos a uma grande variedade de microorganismos presentes especialmente no sangue, na saliva e nas vias aéreas respiratórias dos pacientes ${ }^{1}$. Assim a não utilização ou o uso inadequado de equipamento de proteção individual (EPI) no trabalho odontológico, bem como a manipulação incorreta de objetos contaminados estão associadas à transmissão de várias doenças infectocontagiosas, onde a Hepatite B se sobressai devido alto potencial infeccioso ${ }^{2}$.

A Hepatite B é uma doença ocupacional causada pelo vírus da hepatite B (HBV). É uma das principais doenças hepáticas, apresentando taxas de prevalência variadas, porém altas. A imunização ativa ou passiva contra o HBV é a maneira mais eficaz, acessível e gratuita de prevenção contra esta doença $a^{3-4}$. Tal imunização se dá após a administração de três doses da vacina por via intramuscular. Após a vacinação, mais de $90 \%$ dos adultos jovens e aproximadamente $95 \%$ das crianças e adolescentes são capazes de desenvolver respostas adequadas de anticorpos ${ }^{5}$. No entanto, órgãos de vigilância sanitária estabelecem a necessidade de certificação da imunização através de exames sorológicos AntiHepatite B (Anti-Hb).

Dentre os meios de transmissão do HBV, acidentes ocasionados por picadas de agulhas estão entre os principais responsáveis $(80 \%$ a $90 \%)$ por transmissão entre trabalhadores de saúde. Vale salientar que o risco de transmissão de infecção por meio de material pérfuro-cortante é variável entre os principais agente relacionados com acidentes ocupacionais na odontologia, sendo de 1:3 para HBV, 1:30 para hepatite $\mathrm{C}(\mathrm{HCV})$ e 1:300 para o vírus da imunodeficiência humana $(\mathrm{HIV})^{3}$. Além

\footnotetext{
${ }^{1}$ Cirurgião-dentista

${ }^{2}$ Departamento de Farmacologia e Fisiologia, Universidade Federal do Ceará, Fortaleza, CE, Brasil.

${ }^{3}$ Faculdade de Odontologia, Universidade Federal do Ceará, Sobral, CE, Brasil.

Contatos: epitaciodonto@hotmail.com, caiosdutra@gmail.com, villima@yahoo.com.br, paulagpinheiro@yahoo.com.br
} 
disso, sabe-se que a transmissão do HBV também pode ocorrer através de solução de continuidade em pele e mucosas, relações sexuais, transfusão de sangue e hemoderivados, uso de drogas intravenosas, transmissão vertical e contatos domiciliares ${ }^{6}$.

Apesar de as exposições ocupacionais a materiais biológicos potencialmente contaminados continuarem representando um sério risco aos profissionais da área da saúde, evidências científicas mostram que este tipo de acidente, corresponde à exposição mais frequentemente relatada $^{7}$. O risco ocupacional é variável e dependente do tipo de acidente bem como de outros fatores, como a gravidade, tamanho da lesão, presença e volume de sangue envolvido, além das condições clínicas do paciente-fonte e seguimento adequado pós-exposição ${ }^{8}$. Adicionalmente, alguns trabalhos apresentam outro problema importante, uma vez que, aproximadamente $50 \%$ dos acidentes são sub-notificados ${ }^{9}$. Assim, estima-se que ocorram mais de 800.000 exposições ocupacionais anualmente $^{10}$.

No Brasil o cenário dos acidentes ocupacionais envolvendo material biológico é semelhante aos observados em outros países, quando se compara à incidência de acidentes e de sub-notificações. Um estudo, avaliando a subnotificação em um hospital universitário de São Paulo, mostrou de 41\% a 49\% de subnotificação de acidentes. As justificativas apontadas por profissionais para a não-notificação do acidente baseavam-se no desconhecimento sobre os riscos e/ou não necessidade de notificação ${ }^{11}$.

Desta forma, a fim de se minimizar os riscos de acidentes ocupacionais em odontologia, profissionais devem ser incentivados a adotar medidas básicas de prevenção, tais como a higienização das mãos, uso adequado de EPI, realizar a imunização, manipular e descartar adequadamente materiais pérfuro-cortante ${ }^{12}$. Ainda sim, diante da falha em medidas preventivas o profissional deve estar ciente de que, acidente com material biológico é considerado uma urgência médica, sendo indicado o atendimento o mais cedo possível. A terapia em casos de acidente de trabalho, contendo sangue e outros fluidos corpóreos, é baseada em quimioprofilaxia e deve ser iniciada logo após a exposição, a fim de se obter uma melhor eficácia. Desta forma o objetivo deste estudo foi determinar a prevalência de exposições ocupacionais a material biológico de paciente, e a situação vacinal contra hepatite $\mathrm{B}$ entre acadêmicos de Odontologia.

\section{MATERIAIS E MÉTODOS}

A população deste estudo piloto constituiu-se de alunos de graduação em Odontologia do Curso de Odontologia da Faculdade Católica Rainha do Sertão, bem como cirurgiões-dentistas (CD) profissionais vinculados a rede pública e privada de atendimento da sede do município de Quixadá-CE, Brasil. A aplicação dos questionários ocorreu entre os meses de junho a setembro de 2011. Os sujeitos da pesquisa foram selecionados aleatoriamente com base nos seguintes critérios inclusão: acadêmico do curso de Odontologia com 18 anos de idade ou mais, cursando entre o $4^{\circ}$ e $8^{\circ}$ semestre, bem como CD da rede pública e privada vinculados à sede do município.

Este estudo, transversal foi realizado por um único pesquisador, que realizou uma breve explanação sobre os objetivos do estudo e modo de preenchimento do questionário. Em seguida os questionários eram entregues, o pesquisador se retirava da sala e após o preenchimento os alunos retornavam os questionários preenchidos ou não. Vale salientar que os indivíduos não deveriam se identificar ao preencher o instrumento da pesquisa. Os questionários foram aplicados no período da manhã, nas salas de aula da faculdade ou nos postos de saúde/clínicas particulares.

Os questionários continham perguntas sobre exposições ocupacionais à material biológico bem como a conduta frente à exposição, nos últimos 3 anos, e a situação vacinal contra Hepatite B.

Todos os procedimentos de pesquisa obedeceram à Resolução no . 196/96 do Conselho nacional de Saúde. O estudo foi aprovado pelo Comitê de Ética em Pesquisa (CEP) da Academia Cearense de Odontologia, sob protocolo $\mathrm{n}^{\circ}$ 098. Cada voluntário, após completa explanação sobre o estudo, expressou a sua participação voluntária assinando o Termo de Consentimento Livre e Esclarecido (TCLE).

\section{RESULTADOS \\ Análise geral da população estudada}

Neste estudo foram aplicados 50 questionários para os alunos de graduação em odontologia e para os profissionais da rede pública e privada do município. No entanto apenas 32 (64\%) foram respondidos e devolvidos. A faixa etária dos entrevistados variou de 19 a 45 anos de idade, sendo 15 deles (47\%) do sexo masculino e 17 do sexo feminino (53\%). Quanto a instituição de origem, 24 (75\%) eram alunos de graduação em odontologia, 7 (22\%) eram de CD da rede privada e $1(3 \%)$ era $\mathrm{CD}$ vinculado à rede pública do município. Em relação à distribuição geral dos acidentes ocupacionais, 19 deles (59\%) relataram nunca ter sofrido qualquer acidente, enquanto 13 (41\%) afirmaram já terem experimentado algum tipo de acidente ocupacional.

\section{Análise da população que não sofreu acidente ocupacional}

A distribuição da população de indivíduos que relatou nunca ter sofrido acidente ocupacional se deu da seguinte forma: 10 eram do sexo masculino (53\%) e 9 do sexo feminino (47\%); 15 afirmaram ser graduandos 
em Odontologia (79\%), 4 CD da rede privada (21\%) e nenhum disse ser da rede pública.

\section{Análise da população que sofreu acidente ocupacional \\ Identificação dos entrevistados}

Dentre os sujeitos que relataram episódio de acidente, observou-se que 5 eram do sexo masculino (38\%) e 8 do sexo feminino (62\%). Do total, 9 eram acadêmicos do curso de odontologia (69\%), 3 eram CD da rede privada $(23 \%)$ e 1 era $\mathrm{CD}$ da rede pública $(8 \%)$.

\section{Característica do acidente}

Quanto ao período do acidente, 7 entrevistados disseram não lembrar da época de ocorrência (53\%). Apesar de a maioria dos indivíduos não lembrar o horário em que o acidente tinha ocorrido (54\%), o turno matutino foi o mais relacionado a acidentes $(38 \%)$, seguido pelo turno vespertino (8\%). O turno da noite não foi indicado por nenhum dos entrevistados. No que diz respeito à frequência dos acidentes, 7 entrevistados relataram ter sofrido acidente ocupacional apenas 1 vez (54\%), 4 mais de uma vez (31\%) e 2 não lembravam (15\%).

O tempo de procura de atendimento após contaminação com objeto pérfuro-cortante mostrou que 8 indivíduos (62\%) não procuraram nenhum tipo de atendimento. Três entrevistados não lembravam se haviam procurado atendimento após perfuração $(23 \%)$ e 2 procuraram atendimento imediato, ou seja em tempo inferior a $<2$ horas $(15 \%)$. Vale salientar que todos os entrevistados relataram estar usando EPI no momento do acidente. Os materiais causadores das perfurações mais citados foram: agulha gengival e sonda exploradora, seguidas pela agulha de sutura. Um caso de perfuração com lâmina de bisturi foi relatado. Nenhum caso foi documentado em relação a perfuração causada por limas endodônticas (Figura $1)$.

A maioria do grupo de entrevistados citou a lesão percutânea como o tipo mais frequente de exposição, sendo seguidos de exposição em que houve contato com sangue, tecidos e fluidos corporais (Figura 2).

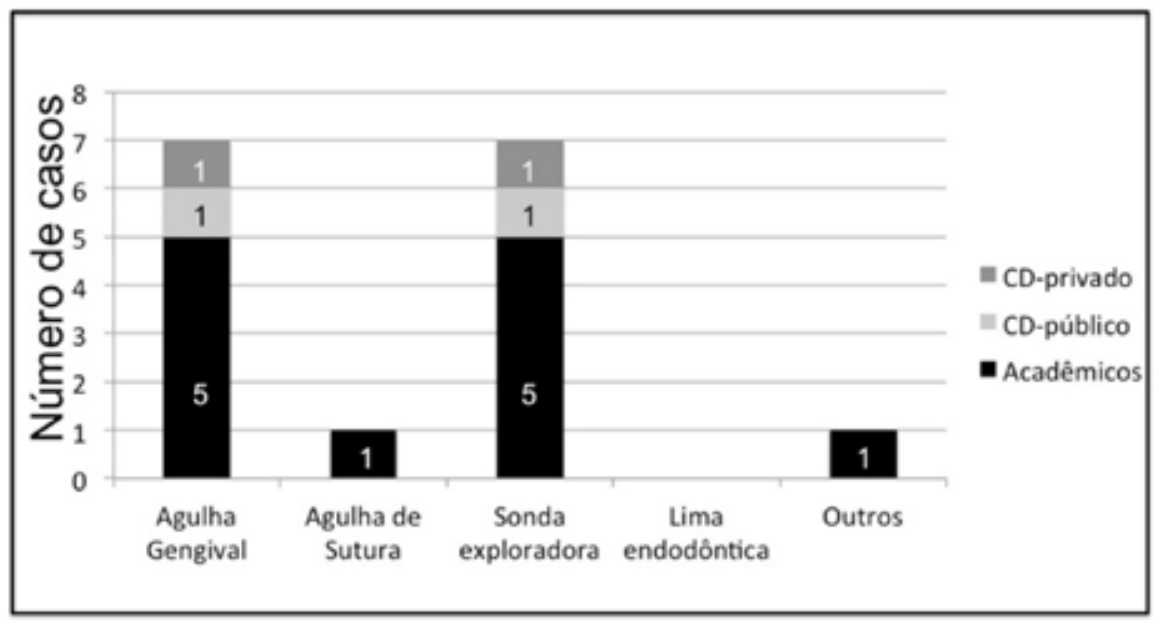

Figura 1 - Distribuição do tipo de material pérfuro-cortante mais relacionado com os acidentes ocupacionais em ambiente odontológico.

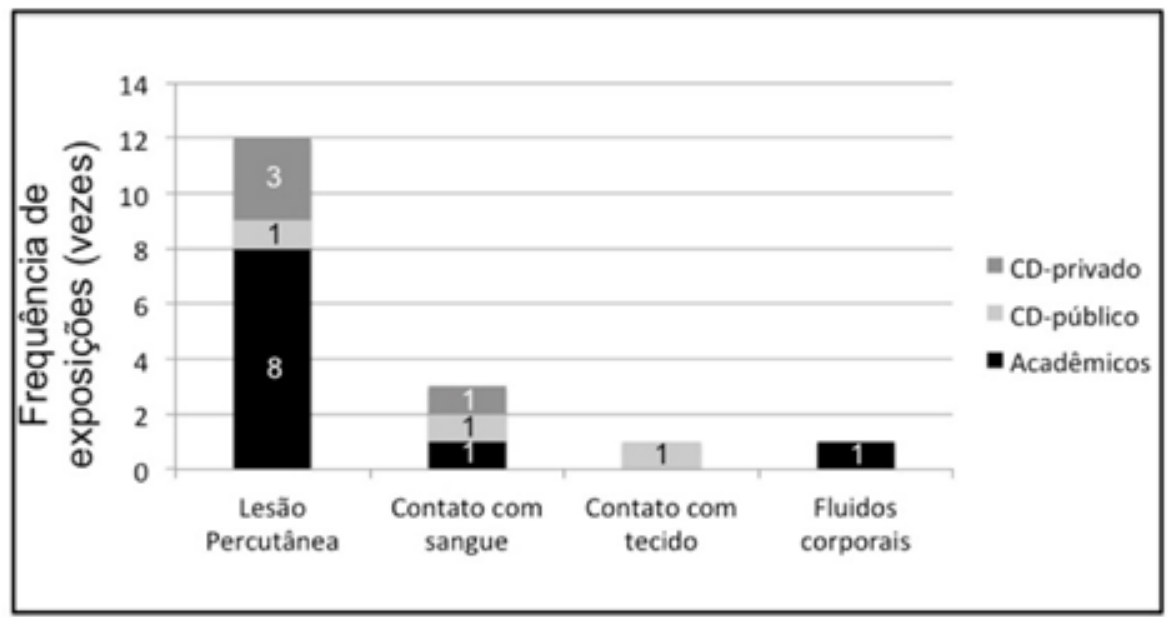

Figura 2 - Distribuição do tipo de exposição mais relacionado com os acidentes ocupacionais em ambiente odontológico. 
Dentre os locais onde ocorreu o acidente ocupacional, a maioria relatou serem os dedos das mãos os locais mais acometidos. Outros locais também citados foram a pele não integra e as mãos. Nenhum dos entrevistados citou acidente envolvendo mucosa alveolar e/ou nasal (Figura 3). As especialidades mais relacionadas aos acidentes foram cirurgia e periodontia.

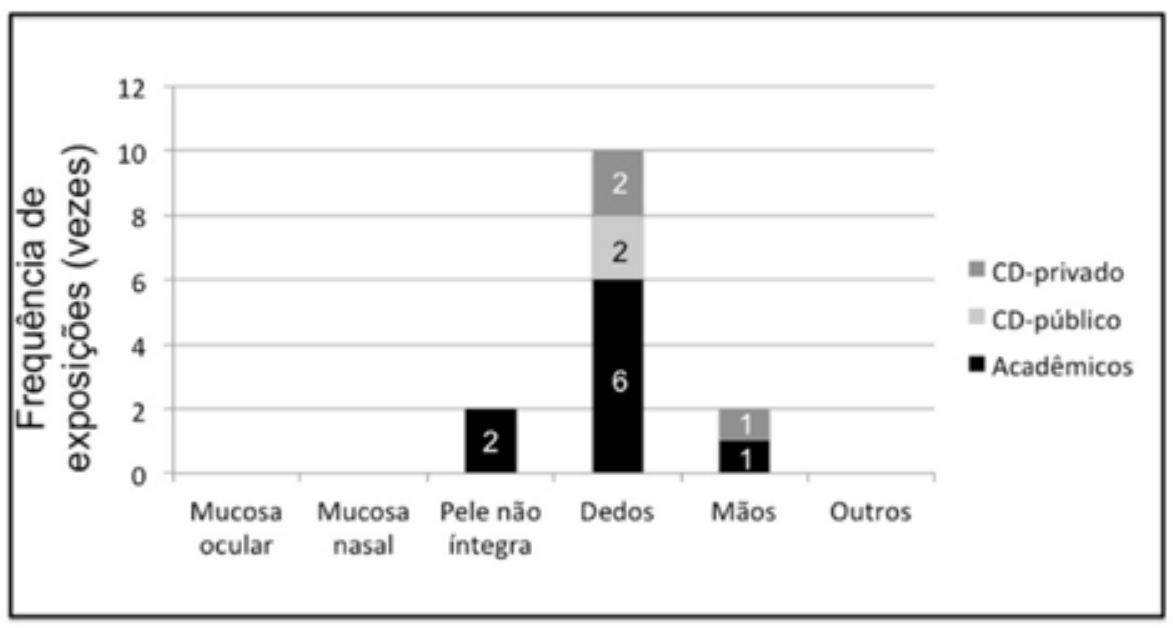

Figura 3 - Distribuição do local de exposição mais relacionado com os acidentes

\section{Conduta frente à exposição}

Após o acidente, todos os 13 participantes afirmaram ter realizado algum tipo conduta. Analisando o tipo de conduta adotada observou-se que a maioria dos entrevistados afirmou ter interrompido o atendimento, removido a luva e localizado da lesão; ter feito a lavagem imediata com sabão e água corrente; ter questionado o paciente quanto a ele ser portador de HIV/AIDS, Hepatite B ou C, alguma DST ou usuário de drogas injetáveis.

Grande parte dos entrevistados relatou não ter perguntado ao paciente sobre o aceite em fornecer amostras sanguíneas para testar a presença de patógenos; não ter procurou atendimento médico; e não ter notificado o acidente à comissão de biossegurança da faculdade ou órgão superiores (Tabela 1).

A identificação do paciente-fonte foi realizada em $61 \%$ dos casos pelos entrevistados. Quatro indivíduos não realizaram tal identificação (31\%) e 1 não lembra de ter feito este procedimento $(8 \%)$. A imunização contra a Hepatite B foi feita em $83 \%$ dos entrevistados. Apenas 1 deles afirmou não ter se submetido a imunização. Dentre os sujeitos que relataram imunização, $66 \%$ confirmaram ter feito o esquema vacinal completo, a vacinação até a terceira dose. 33\% afirmaram ter tomado até a segunda dose e 1 disse ter recebido somente uma dose da vacina conta hepatite B. Ainda sim, 3 entrevistados realizaram sorologia anti-Hb para confirmação da imunização (23\%). Oito indivíduos não a realizaram sorologia anti-Hb (62\%). Nenhum dos entrevistados relatou ter feito quimioprofilaxia com anti-retrovirais após o acidente ocupacional.

\section{DISCUSSÃO}

O estudo mostrou um índice de desistência de mais de 30\%. Tal índice talvez se deva a negligência e descaso com relação ao assunto ${ }^{13}$.

Em relação aos acidentes com material biológico, houve maior prevalência de acidentes no sexo feminino, conforme os resultados de alguns estudos ${ }^{1,14-16}$. Por outro lado, outros levantamentos não foram capazes de detectar tal predileção ${ }^{10}$. No entanto, ainda não está bem esclarecido se as mulheres estão realmente relacionadas a um grande número de episódios de exposição ocupacional ou se, este grupo de indivíduos notificam mais os acidentes ocupacionais, ou ambos.

Estudantes apresentam maior frequência de acidentes ${ }^{17}$, por tomarem parte na realização de diversos procedimentos e, muitas vezes, estarem associados à falta de conhecimento adequado sobre as medidas de precauções universais e treinamento repetido sob supervisão apropriada, bem como ao nervosismo e/ou inexperiência durante os procedimentos. Embora o tempo de atendimento clínico seja um fator importante na frequência de acidentes com material biológico, devido à maior exposição ao risco, não se pode negar a importância do fator experiência na prática clínica que contribui para a redução de acidentes em decorrência do maior domínio das técnicas e habilidades ${ }^{4}$.

O maior número de acidentes está relacionado ao segundo semestre do ano. Um único estudo, também analisando esta correlação observou maior frequência de acidentes durante os meses de julho a setembro ${ }^{18}$. Embora mais estudos sejam necessários, o aumento do estresse, cansaço físico bem como emocional parecem 
Tabela 1. Distribuição da conduta frente à exposição ocupacional em ambiente odontológico.

\begin{tabular}{|c|c|c|c|}
\hline Variáveis & $\begin{array}{l}\text { Sim } \\
\text { N (\%) } \\
\end{array}$ & $\begin{array}{l}\text { Não } \\
\text { N (\%) } \\
\end{array}$ & $\begin{array}{l}\text { Não Lembra } \\
\text { N (\%) }\end{array}$ \\
\hline \multicolumn{4}{|l|}{ Interrupção do atendimento } \\
\hline Acadêmico & $9(6,9 \%)$ & 0 & 0 \\
\hline CD-público & $1(0,7 \%)$ & $1(0,7 \%)$ & 0 \\
\hline CD-privado & $1(0,7 \%)$ & 0 & $1(0,7 \%)$ \\
\hline \multicolumn{4}{|l|}{ Lavagem com água e sabão } \\
\hline Acadêmico & $9(6,9 \%)$ & 0 & 0 \\
\hline CD-público & $1(0,7 \%)$ & $1(0,7 \%)$ & 0 \\
\hline CD-privado & $2(1,5 \%)$ & 0 & 0 \\
\hline \multicolumn{4}{|c|}{ Questionamento sobre HIV/hepatite } \\
\hline Acadêmico & $9(6,9 \%)$ & 0 & 0 \\
\hline CD-público & $1(0,7 \%)$ & $1(0,7 \%)$ & 0 \\
\hline CD-privado & $1(0,7 \%)$ & $1(0,7 \%)$ & 0 \\
\hline \multicolumn{4}{|c|}{ Questionamento sobre coleta de amostra } \\
\hline Acadêmico & $1(0,7 \%)$ & $8(6,1 \%)$ & 0 \\
\hline CD-público & 0 & $1(0,7 \%)$ & $1(0,7 \%)$ \\
\hline CD-privado & 0 & $1(0,7 \%)$ & $1(0,7 \%)$ \\
\hline \multicolumn{4}{|l|}{ Atendimento médico } \\
\hline Acadêmico & $1(0,7 \%)$ & $8(6,1 \%)$ & 0 \\
\hline CD-público & $1(0,7 \%)$ & $1(0,7 \%)$ & 0 \\
\hline CD-privado & 0 & $1(0,7 \%)$ & $1(0,7 \%)$ \\
\hline \multicolumn{4}{|l|}{ Notificação } \\
\hline Acadêmico & $1(0,7 \%)$ & $8(6,1 \%)$ & 0 \\
\hline CD-público & $1(0,7 \%)$ & $1(0,7 \%)$ & 0 \\
\hline CD-privado & 0 & $1(0,7 \%)$ & $1(0,7 \%)$ \\
\hline
\end{tabular}

estar associados. Durante o dia de trabalho, o turno matutino pareceu ser o mais relacionado a acidentes, talvez devido ao maior número de atividades clínicas serem realizadas durante este horário aumentando o risco de exposição a acidentes ${ }^{11}$. Este dado ainda parece controverso, pois foi demonstrado de que $76 \%$ dos acidentes clínicos ocorreram após 13:30 horas enquanto que apenas 15\% ocorreram entre 9:00 e 10:00 horas da manhã ${ }^{18}$.

O uso de EPI é fundamental para uma prática segura em instituições de saúde. Entretanto, esta segurança se efetivará não apenas pela adoção destes equipamentos, mas pela forma como são utilizados. O estudo mostra a conscientização dos entrevistados em relação à importância do uso dos EPI durante suas atividades clínicas, uma vez que todos relataram fazer uso destas medidas preventivas. Outros estudos, no entanto, não observaram tamanha adoção a este tipo de medida enquanto outros descreveram variação de $33,8 \%$ a $90,8 \%$ quanto ao uso de $\mathrm{EPI}^{17}$.

A agulha gengival e a sonda exploradora estão entre os instrumentos odontológicos mais relacionados a acidentes ocupacionais, corroborando achados de outros estudos ${ }^{15-17,19}$, provavelmente devido à presença constante destes instrumentais nos diversos procedimentos odontológicos. Com base nesta relação e na anatomia destes instrumentais, lesão percutâneas são as mais associadas aos acidentes ocupacionais ${ }^{14,17,19-20}$, aumentando o risco de infecções como HIV/AIDS e Hepatites B e C. Portanto é questão prioritária a adoção de medidas de prevenção e controle de riscos ocupacionais aos acidentes com agulhas que deve se iniciar com análise cuidadosa das fontes potenciais de risco, procurando caracterizar as situações de ocorrência e os padrões de tendência.

Os dedos são relatados como a região do corpo mais afetada quando de um acidente ocupacional ${ }^{14,17-18}$ confirmando os achados deste estudo. Devido à proximidade com os instrumentos em sua ação, esta região tem uma maior chance de ser lesionada. O uso de luvas não resultou na redução da ocorrência de lesões percutâneas nos dedos e mãos. Porém, durante os procedimentos odontológicos, a contaminação da saliva com sangue é previsível e o trauma às mãos dos profissionais é comum. $\mathrm{O}$ uso de luvas minimiza o potencial para o contato de pele não intacta dos profissionais da odontologia com a saliva contaminada com sangue dos pacientes. As luvas cirúrgicas não impedem a ocorrência de lesões percutâneas. Entretanto, se estas ocorrerem, a 
interferência das luvas reduz a quantidade de material biológico inoculado, podendo reduzir, igualmente, a possibilidade de aquisição de patógenos em alguns casos $^{14}$.

A maioria dos entrevistados afirmou ter realizado condutas individuais básicas pós-exposição, corroborando achados de outros estudos. Um estudo relatou que $98,5 \%$ dos profissionais lavaram o local do acidente, $44,6 \%$ perguntaram ao paciente sobre HIV/hepatite ${ }^{20}$. No entanto, este estudo, em concordância com outros mostraram que a maioria dos acidentados não solicitou exames ao paciente, buscou atendimento médico, notificou o acidente, ou tenha feito algum tipo de quimioprofilaxia ${ }^{20}$. O atraso no tempo de procura de atendimento após contaminação com objeto pérfuro-cortante ou até mesmo a nãoprocura de atendimento, reflete despreocupação dos entrevistados quanto ao risco de infecções. Apenas $15 \%$ procuraram atendimento imediato. A avaliação da exposição realizada por um profissional médico especializado é fundamental para determinar a severidade da lesão e indicar ou não a profilaxia pós-exposição ${ }^{20}$. Para exposições com risco mínimo a profilaxia não é justificada, devido aos efeitos colaterais da medicação. Porém, quando indicada, a quimioprofilaxia anti-HIV é capaz de reduzir o risco de aquisição do HIV em até $81 \%$ após lesão percutânea, mas para isso ela deve ser administrada o mais breve possível, preferencialmente nas duas primeiras horas após a exposição ${ }^{8}$. Vale salientar que a identificação do paciente-fonte, foi realizada por grande parte dos entrevistados, é um achado positivo diante de uma comunicação futura com o paciente.

Com relação à proteção contra Hepatite $B$, embora a maioria dos entrevistados tenha relatado vacinação prévia, apenas $23 \%$ apresentaram resultado reagente positivo para anticorpo anti-HB. Este dado confirma os achados de outro estudo, onde 91,3\% dos acidentados relatou vacinação contra HBV, porém apenas $73 \%$ realizaram sorologia anti- $\mathrm{Hb}^{14}$. A dosagem de anti-HBs de rotina pode indicar que os profissionais não estejam protegidos contra a infecção pelo HBV, por não completarem o esquema vacinal ou não apresentarem resposta vacinal, no entanto, vale salientar que este exame pós-imunização não é necessário. Esta análise deve ser feita um a dois meses após a terceira dose da vacina nos seguintes casos: pacientes em hemodiálise, pessoas com infecção pelo HIV, profissionais com risco de exposição ao vírus, pacientes imunocomprometidos, parceiros sexuais de pessoas HBsAg positivo e crianças nascidas de mães HBsAg positivo ${ }^{21}$.

Com base dos resultados deste estudo, foi proposto, dentro da faculdade de odontologia, um programa de formação e atualização dos estudantes e profissionais sobre a importância da prevenção de acidentes ocupacionais, bem como necessidade dos procedimentos de notificação imediata de acidentes.

\section{CONCLUSÃO}

A prevalência de exposição ocupacional à material biológico entre os graduandos e odontólogos da rede pública e privada investigados foi alta.

A situação vacinal contra a Hepatite $B$ mostrou-se precária, uma vez que apenas uma minoria completou o esquema profilático.

\section{ABSTRACT}

Aim: To determine the prevalence of occupational accidents and vaccinal status against Hepatitis B among dental students and professional dentists. Materials and Methods: This pilot study, in descriptive character, used an applied questionnaire to collect relevant data that contemplated items of subject identification, accident characteristics, and conduct referent to dental exposure. This study's sample consisted of dental students from Rainha do Sertão Catholic University (FCRS) and professionals from Quixadá, Ceará, Brazil. Results: Thirty-two individuals were interviewed. Of these individuals, $59 \%$ reported that they had never suffered any kind of accident, while $41 \%$ had already experienced some type of occupational accident. Among those who reported injuries, $38 \%$ were male and $62 \%$ female. The instruments most related to accidents included: gingival needle and dental probe. In the majority of cases, the accidents were of the percutaneous type, although $100 \%$ of the individuals had confirmed the use of individual protection equipment. Regarding vaccinal status against hepatitis $B$, although the majority of the interviewed individuals had reported prior vaccination $(83 \%)$, only $23 \%$ presented a serology to the anti-Hb antibody. Conclusion: Despite the reduced sample size, the prevalence of occupational exposure to biological material is high, and the vaccinal status against Hepatitis B it is still poor among dental students and dental professionals in Quixadá

Uniterms: Occupational health. Hepatitis B. Occupational exposure.

\section{REFERÊNCIAS}

1. Garbin CAS, Martins RJ, Garbin AJI, Hidalgo LRC. Contuctas de estudiantes del área de la salud frente a la exposición ocupacional a material biológico. Cienc Trab. 2009;11:18-21.

2. Neuman H. Occupational hazards in dentistry. Refuat Hapeh Vehashinayim. 2011;28(3):72.

3. Fitzsimons D, Hendrickx G, Vorsters A. Hepatitis B vaccination: a completed schedule enough to control HBV lifelong?: Milan, Italy, 17-18 November 2011. Vaccine. 2013; 31:584. 
4. Ribeiro PHV, Hayashida MM, Moriya TM. Acidentes com material biológico entre esstudantes de graduação em odontologia. Rev Odontol Univ Cid de São Paulo. 2007;19: 263-8.

5. Kalyoncu D, Urganci N. Response to hepatitis $\mathrm{A}$ and $\mathrm{B}$ vaccination in patients with chronic hepatitis C: 8-year follow-up. Paediatr Int Child Health. 2012;32(3):136-9.

6. El-Serag HB. Epidemiology of viral hepatitis and hepatocellular carcinoma.

7. Gastroenterology. 2012;142(6):1264-73.

8. Sêcco IA, Robazzi ML, Shimizu DS, Rúbio MM. Typical occupational accidents with employees of a university hospital in the south of Brazil: epidemiology and prevention. Rev Latinoam Enferm. 2008;16(5):824-31.

9. Cardo DM, Culver DH, Ciesielski CA, Srivastava PU, Marcus R, Abiteboul D, et al. A case-control study of HIV seroconversion in health care workers after percutaneous exposure. New Engl Med. 1997;337:1485-90.

10. Henry K, Campbell S. Needlestick/sharps injuries and HIV exposure among health care workers: national estimates based on a survey of U.S. hospitals. Minn Med. 1995;78:41-4.

11. Hämäläinen $\mathrm{P}$, Leena Saarela $\mathrm{K}$, Takala J. Global trend according to estimated number of occupational accidents and fatal work-related diseases at region and country level. J Safety Res. 2009;40(2):125-39.

12. Marziale MHP, Silva EJ, Haas VJ, Robazzi MLCC. Acidentes com material biológico em hospital da rede de prevenção de acidentes do trabalho-REPAT. Rev Bras de Saúde Ocup. 2007;32:109-19.

13. Ngatu NR, Phillips EK, Wembonyama OS, Hirota R, Kaunge NJ, Mbutshu LH, et al. Practice of universal precautions and risk of occupational blood-borne viral infection among Congolese health care workers. Am J Infect Control. 2012;40(1):68-70.
14. Leite MAA. Caracterização da conduta dos cirurgiões dentistas de Belo Horizonte frente aos procedimentos de controle de infecção cruzada: uma perspectiva epidemiológica [dissertação]. Belo Horizonte: Instituto de Ciências Biológicas da Universidade Federal de Minas Gerais; 1996.

15. Silva JA, Paula VS, Almeida AJ, Villar LM. Investigação de acidentes biológicos entre profissionais de saúde. Esc Anna Nery Rev Enferm. 2009;13(3):508-16.

16. Machado-Carvalhais HP, Ramos-Jorge ML, Auad SM, Martins LHPM, Paiva SM, Pordeus IA. Occupational exposure to potentially infectious biological material in a dental teaching environment. J Dent Educ. 2008;72:1201-8.

17. Wood AJ, Nadershahi NA, Fredekind RE, Cuny EJ, Chambers DW. Student occupational exposure incidence: perception versus reality. J Dent Educ. 2006;70:1081-8.

18. Wicker S, Rabenau HF. Occupational exposures to bloodborne viruses among German dental professionals and students in a clinical setting. Int Arch Occup Environ Health. 2010;83(1):77-83.

19. Callan RS, Caughman F, Budd ML. Injury reports in a dental school: a two-year overview. J Dent Educ. 2006;70:1081-8.

20. Cleveland JL, Barker LK, Cuny EJ, Panlilio AL. National Surveillance System for Health Care Workers Group. Preventing percutaneous injuries among dental health care personnel. J Am Den Assoc. 2007;138:169-78

21. Garcia LP, Blank VL. Management of occupational exposures to potentially infectious materials in dentistry. Rev Saúde Pública. 2008;42:279-86.

22. American Academy of Pediatrics. Hepatitis B. In: Peter G. Red book: report of the Committee on Infectious Diseases. $25^{\text {nd }}$ ed., Elk Grove Village: American Academy of Pediatrics; 2003. p. 31636. 